University of Wollongong

Research Online

Australian Institute for Innovative Materials -

Papers

Australian Institute for Innovative Materials

$1-1-2010$

\title{
Magnetotransport of La0.70ca0.3-xsrxmno3(Ag): A potential room temperature bolometer and magnetic sensor
}

\author{
V P. Awana \\ National Physical Laboratory, New Delhi \\ Rahul Tripathi \\ CSIR, New Delhi \\ Neeraj Kumar \\ CSIR, New Delhi \\ H Kishan \\ National Physical Laboratory, New Delhi \\ g v. Bhalla \\ University of Delhi
}

See next page for additional authors

Follow this and additional works at: https://ro.uow.edu.au/aiimpapers

Part of the Engineering Commons, and the Physical Sciences and Mathematics Commons

Research Online is the open access institutional repository for the University of Wollongong. For further information contact the UOW Library: research-pubs@uow.edu.au 


\title{
Magnetotransport of La0.70ca0.3-xsrxmno3(Ag): A potential room temperature bolometer and magnetic sensor
}

\author{
Abstract

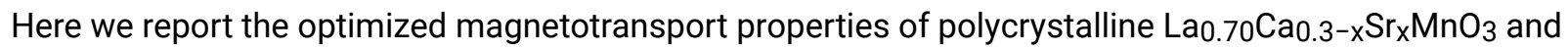 \\ their composites with $\mathrm{Ag}$. The optimization was carried out by varying the $\mathrm{Sr}$ and $\mathrm{Ag}$ contents \\ simultaneously to achieve large temperature coefficient of resistance (TCR) as well as low field \\ magnetoresistance (MR) at room temperature. Sharpest paramagnetic (PM)-ferromagnetic (FM) and \\ insulator-metal $(I M)$ transition is observed in the vicinity of the room temperature $\left(T_{C} \approx 300 \mathrm{~K} \approx T_{I M}\right)$ for \\ the composition La0.70Ca0.20Sr0.10MnO3:Ag0.20. Partial substitution of larger $\mathrm{Sr}^{2+}$ ions at the $\mathrm{Ca}^{2+}$ ions \\ sites controls the magnitude of the FM and IM transition temperatures, while the Ag induces the desired \\ sharpness in these transitions. For the optimized composition, maximum TCR and MR are tuned to room \\ temperature $(300 \mathrm{~K})$ with the former being as high as $9 \%$ and the later being $20 \%$ and $\sim 30 \%$ at 5 and 10 \\ kOe magnetic fields respectively. Such sharp single peak (TCR 9\%) at room temperature can be used for \\ the bolometric and infrared detector applications. The achievement of large TCR and low field MR at \\ $\mathrm{T} \sim 300 \mathrm{~K}$ in polycrystalline samples is encouraging and we believe that further improvements can be \\ achieved in thin films which by virtue of their low conduction noise are more suitable for device \\ applications.
}

\section{Keywords}

Magnetotransport, la0, 70ca0, xsrxmno3, potential, room, temperature, bolometer, magnetic, sensor

Disciplines

Engineering | Physical Sciences and Mathematics

\section{Publication Details}

Awana, VP, Tripathi, R, Kumar, N, Kishan, H, Bhalla, GL, Zeng, R, Chandra, L Sharth, Ganesan, V \& Habermeier, HU (2010), Magnetotransport of La0.70ca0.3-xsrxmno3(Ag): A potential room temperature bolometer and magnetic sensor, In Proceedings of the 11TH Joint MMM-Intermag Conference, Washington, DC, 2010, 18-22 Jan, Washington, DC, Journal Of Applied Physics, 107(9),

\section{Authors}

V P. Awana, Rahul Tripathi, Neeraj Kumar, H Kishan, g v. Bhalla, Rong Zeng, L.S Sharth Chandra, V Ganesan, and H U. Habermeier 


\title{
Magnetotransport of $\mathrm{La}_{0.70} \mathrm{Ca}_{0.3-\mathrm{x}} \mathrm{Sr}_{\mathrm{x}} \mathrm{MnO}_{3}(\mathrm{Ag})$ : A potential room temperature bolometer and magnetic sensor
}

\author{
V. P. S. Awana, ${ }^{1, a)}$ Rahul Tripathi, ${ }^{1}$ Neeraj Kumar, ${ }^{1}$ H. Kishan, ${ }^{1}$ G. L. Bhalla, ${ }^{2}$ R. Zeng, ${ }^{3}$ \\ L. S. Sharth Chandra, ${ }^{4}$ V. Ganesan, ${ }^{5}$ and H. U. Habermeier ${ }^{6}$ \\ ${ }^{1}$ National Physical Laboratory (CSIR), Dr. K.S. Krishnan Marg, New Delhi 110012, India \\ ${ }^{2}$ Department of Physics and Astrophysics, University of Delhi, Delhi-110007, India \\ ${ }^{3}$ ISEM, University of Wollongong, New South Wales 2522, Australia \\ ${ }^{4} U G C-D A E$ Consortium for Scientific Research, University Campus, Khandwa Road, Indore 452017, India \\ and Material and Advanced Accelerator Science Division, RRCAT, Indore 452013, India \\ ${ }^{5}$ UGC-DAE Consortium for Scientific Research, University Campus, Khandwa Road, Indore 452017, India \\ ${ }^{6}$ Max Planck Institute for Solid State Research, Heisenbergstrasse-1, D-70569 Stuttgart, Germany
}

(Presented 19 January 2010; received 30 October 2009; accepted 20 November 2009; published online 6 May 2010)

\begin{abstract}
Here we report the optimized magnetotransport properties of polycrystalline $\mathrm{La}_{0.70} \mathrm{Ca}_{0.3-\mathrm{x}} \mathrm{Sr}_{\mathrm{x}} \mathrm{MnO}_{3}$ and their composites with $\mathrm{Ag}$. The optimization was carried out by varying the $\mathrm{Sr}$ and $\mathrm{Ag}$ contents simultaneously to achieve large temperature coefficient of resistance (TCR) as well as low field magnetoresistance (MR) at room temperature. Sharpest paramagnetic (PM)-ferromagnetic (FM) and insulator-metal (IM) transition is observed in the vicinity of the room temperature $\left(\mathrm{T}_{\mathrm{C}} \approx 300 \mathrm{~K}\right.$ $\approx \mathrm{T}_{\mathrm{IM}}$ ) for the composition $\mathrm{La}_{0.70} \mathrm{Ca}_{0.20} \mathrm{Sr}_{0.10} \mathrm{MnO}_{3}: \mathrm{Ag}_{0.20}$. Partial substitution of larger $\mathrm{Sr}^{2+}$ ions at the $\mathrm{Ca}^{2+}$ ions sites controls the magnitude of the FM and IM transition temperatures, while the $\mathrm{Ag}$ induces the desired sharpness in these transitions. For the optimized composition, maximum TCR and MR are tuned to room temperature $(300 \mathrm{~K})$ with the former being as high as $9 \%$ and the later being $\sim 20 \%$ and $\sim 30 \%$ at 5 and 10 kOe magnetic fields respectively. Such sharp single peak (TCR $\sim 9 \%)$ at room temperature can be used for the bolometric and infrared detector applications. The achievement of large TCR and low field MR at T $300 \mathrm{~K}$ in polycrystalline samples is encouraging and we believe that further improvements can be achieved in thin films which by virtue of their low conduction noise are more suitable for device applications. (C) 2010 American Institute of Physics. [doi:10.1063/1.3365412]
\end{abstract}

\section{INTRODUCTION}

Manganites with general formula $\mathrm{A}_{1-\mathrm{x}} \hat{\mathrm{A}}_{\mathrm{x}} \mathrm{MnO}_{3}$ (where $\mathrm{A}=$ rare earth element and $\mathrm{A}=$ Alkaline earth metals) are a focal point of research since a long time. ${ }^{1}$ These compounds are considered to be promising material for the technological opinion. ${ }^{1-3}$ Among all fascinating properties, the most outstanding and extensively explored assets are the magnetoresistance (MR) and temperature coefficient of resistance (TCR). MR is the relative change in the electrical resistivity by application of magnetic field and similarly TCR is parametric notation of transition sharpness, defined as, $\left[1 / R^{*}(d R / d T)\right]$, where $R$ and $T$ are the resistance and temperature, respectively. It is seen that the maximum MR as well as TCR in hole-doped manganites occur near the metalinsulator (MI) transition $\left(\mathrm{T}_{\mathrm{MI}}\right)$ being accompanied with ferromagnetic (FM)-paramagnetic transition. The steep transition about MI crossover determines the sensitivity as well as active zone for these sensors. Practically one desires to have higher TCR and MR near room temperature, i.e., at $300 \mathrm{~K}$.

In this direction there had been various trials before and TCR as high as above $10 \%$ and reasonable MR is seen in

\footnotetext{
${ }^{\text {a) }}$ Author to whom correspondence should be addressed. FAX: 0091-1145609310. Tel.: 0091-11-45608329. Electronic mail: awana@mail.nplindia.ernet.in. URL: www.freewebs.com/vpsawana/.
}

$\mathrm{La}_{2 / 3} \mathrm{Ca}_{1 / 3} \mathrm{MnO}_{3}: \mathrm{Ag}_{\mathrm{y}}$ composites. ${ }^{4-6}$ However the high TCR and optimized reasonable MR, in particular at low fields is always seen at below room temperature $(<265 \mathrm{~K})$ only. ${ }^{4-7}$ As mentioned before for practical use of manganites as sensors, one aspires for high TCR and MR at room temperature. Though, the working temperature could be enhanced to near room temperature in case of $\mathrm{La}_{0.7} \mathrm{Ca}_{0.3-\mathrm{x}} \mathrm{Ba}_{\mathrm{x}} \mathrm{MnO}_{3}$, the observed values of TCR and MR are reasonably good, but could not improved a lot with silver addition. ${ }^{8}$ In fact our earlier efforts in case of $\mathrm{La}_{0.7} \mathrm{Sr}_{0.3} \mathrm{MnO}_{3} / \mathrm{La}_{0.7} \mathrm{Ba}_{0.3} \mathrm{MnO}_{3}$, we were not successful. ${ }^{9}$ In view of our consistent approach to improve room temperature TCR and low field MR (LFMR) in the case of pristine ${ }^{5}$ and $\mathrm{Ba}$ doped $^{8}$ silver composites, in the present paper we deliberate on $\mathrm{Sr}$ doped $\mathrm{La}_{0.7} \mathrm{Ca}_{0.3} \mathrm{MnO}_{3}$ and their $\mathrm{Ag}$ added compounds. For optimized composition of $\mathrm{La}_{0.7} \mathrm{Ca}_{0.20} \mathrm{Sr}_{0.10} \mathrm{MnO}_{3}: \mathrm{Ag}_{0.2}$, the maximum TCR and MR are tuned to $300 \mathrm{~K}$ with the former being as high as $9 \% / \mathrm{K}$ and the later being above $20 \%$ at $5 \mathrm{kOe}$ and $30 \%$ at $10 \mathrm{kOe}$ field. Although the studied samples are bulk in nature, the thin films fabricated from these bulk targets will serve the ultimate purpose of manganite being used as potential magnetic sensors at room temperature. Further above 9\%/K single peak sharp TCR at $300 \mathrm{~K}$ can be used for the bolometric and infrared applications. Improved TCR $(>9 \%)$ and MR ( $>20 \%$ at $5 \mathrm{kOe})$ at $300 \mathrm{~K}$ is the maximum yet reported for any manganite at room temperature or above. 


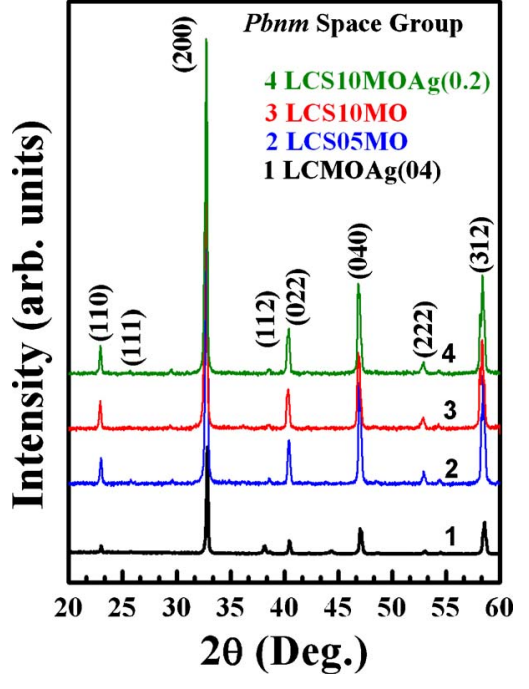

FIG. 1. (Color online) XRD pattern of $\mathrm{La}_{2 / 3} \mathrm{Ca}_{1 / 3} \mathrm{MnO}_{3}: \mathrm{Ag}_{0.4}$, $\mathrm{La}_{0.7} \mathrm{Ca}_{0.25} \mathrm{Sr}_{0.05} \mathrm{MnO}_{3}, \mathrm{La}_{0.7} \mathrm{Ca}_{0.2} \mathrm{Sr}_{0.1} \mathrm{MnO}_{3}$, and $\mathrm{La}_{0.7} \mathrm{Ca}_{0.2} \mathrm{Sr}_{0.1} \mathrm{MnO}_{3}: \mathrm{Ag}_{0.2}$

\section{EXPERIMENTAL DETAILS}

The samples of the series $\mathrm{La}_{0.7} \mathrm{Ca}_{0.3-\mathrm{x}} \mathrm{Sr}_{\mathrm{x}} \mathrm{MnO}: \mathrm{Ag}_{\mathrm{y}}$ ( $\mathrm{x}$ $=0.0,0.05$, and $0.10 ; \mathrm{y}=0,0.1,0.2,0.3$, and 0.4$)$ are synthesized by solid-state reaction route using ingredients $\mathrm{La}_{2} \mathrm{O}_{3}$, $\mathrm{CaCO}_{3}, \mathrm{SrCO}_{3}, \mathrm{MnO}_{2}$, and $\mathrm{Ag}$ (powder). The mixed powders were calcined at 1000,1100 , and $1200{ }^{\circ} \mathrm{C}$ in air for 24 $\mathrm{h}$ and followed by thorough grounding each time. Then the powders were presintered at $1300{ }^{\circ} \mathrm{C}$ in air for $24 \mathrm{~h}$. Finally the pelletized ceramics were annealed in air for $24 \mathrm{~h}$ at $1400{ }^{\circ} \mathrm{C}$. For loading of oxygen, the pellets were annealed in the flow of oxygen at $1100{ }^{\circ} \mathrm{C}$ for $12 \mathrm{~h}$ and subsequently slow cooled to room temperature. The structure and phase purity of the samples were analyzed by powder X-ray diffraction (XRD) taken on Rigaku miniflex diffractometer. The $\mathrm{R}(\mathrm{T})$ measurements with and without magnetic field $(<14 \mathrm{~T})$ were carried out using four-probe method in the temperature range of 5-400K on a Quantum Design Physical Property Measurement System.

\section{RESULTS \& DISCUSSION}

Figure 1 depicts the room temperature XRD patterns of $\mathrm{La}_{0.7} \mathrm{Ca}_{0.25} \mathrm{Sr}_{0.05} \mathrm{MnO}_{3} \quad$ (LCS05MO), $\mathrm{La}_{0.7} \mathrm{Ca}_{0.2} \mathrm{Sr}_{0.1} \mathrm{MnO}_{3}$ (LCS10MO), $\quad \mathrm{La}_{0.7} \mathrm{Ca}_{0.2} \mathrm{Sr}_{0.1} \mathrm{MnO}_{3}: \mathrm{Ag}_{0.2}$ $[\operatorname{LCS} 10 \mathrm{MOAg}(0.2)]$, along with earlier studied $\mathrm{La}_{2 / 3} \mathrm{Ca}_{1 / 3} \mathrm{MnO}_{3}: \mathrm{Ag}_{0.4}\left[(\operatorname{LCMOAg}(0.4)] .^{5}\right.$ All the studied samples are crystallized in near single phase along with some silver lines in $\mathrm{Ag}$ added compounds. Details of structural refinements along with lattice parameters variations will be reported else where in full paper. ${ }^{10}$

The normalized resistance $\left(\mathrm{R}_{\mathrm{T}} / \mathrm{R}_{400 \mathrm{~K}}\right)$ plots for various $\mathrm{Ca} / \mathrm{Sr}$ substituted and $\mathrm{Ag}$ added $\mathrm{LaMnO}_{3}$ samples are shown in Fig. 2. As it is well known that $\mathrm{La}_{0.7} \mathrm{Sr}_{0.3} \mathrm{MnO}_{3}$ has high MI transition temperature $\left(\mathrm{T}_{\mathrm{MI}}\right)$ than $\mathrm{La}_{0.7} \mathrm{Ca}_{0.3} \mathrm{MnO}_{3}$. This change in the transition temperature with divalent ions $(\mathrm{Ca}$, $\mathrm{Sr}$ ) substitution is related to the variation in $\mathrm{Mn}-\mathrm{O}-\mathrm{Mn}$ bond angle governs by the ionic size of the dopant. Tilting of $\mathrm{Mn}-\mathrm{O}$ bond directly affects the electron hopping amplitude from one $\mathrm{Mn}$ site to another $\mathrm{Mn}$ site in these compounds. So,

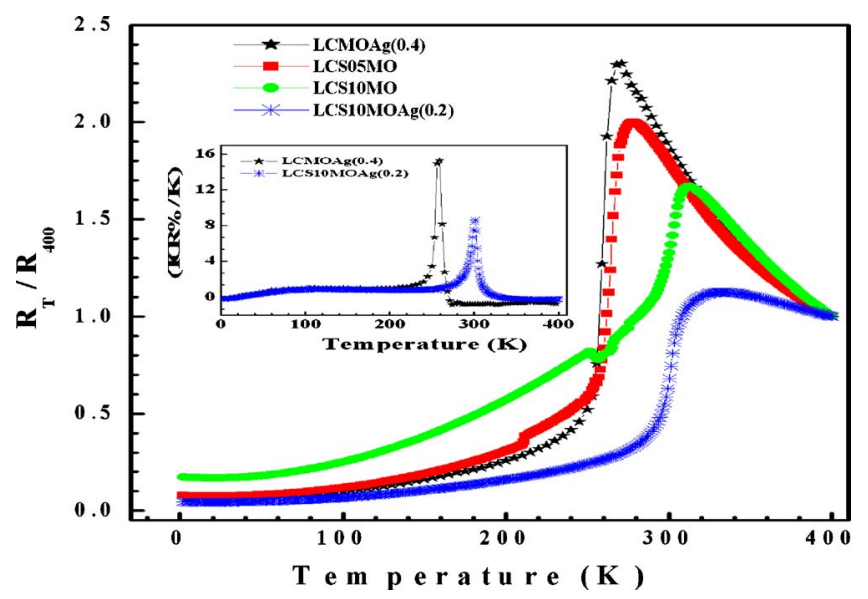

FIG. 2. (Color online) Normalized $\mathrm{R}(\mathrm{t})$ plots of $\mathrm{La}_{2 / 3} \mathrm{Ca}_{1 / 3} \mathrm{MnO}_{3}: \mathrm{Ag}_{0.4}$, $\mathrm{La}_{07} \mathrm{Ca}_{0.25} \mathrm{Sr}_{0.05} \mathrm{MnO}_{3}, \mathrm{La}_{07} \mathrm{Ca}_{0.2} \mathrm{Sr}_{0.1} \mathrm{MnO}_{3}$, and $\mathrm{La}_{07} \mathrm{Ca}_{02} \mathrm{Sr}_{0.1} \mathrm{MnO}_{3}: \mathrm{Ag}_{0.2}$. Inset shows the TCR percent as a function of temperature for $\mathrm{La}_{2 / 3} \mathrm{Ca}_{1 / 3} \mathrm{MnO}_{3}: \mathrm{Ag}_{0.4}$ and $\mathrm{La}_{0.7} \mathrm{Ca}_{0.2} \mathrm{Sr}_{0.1} \mathrm{MnO}_{3}: \mathrm{Ag}_{0.2}$.

by proper optimization of $\mathrm{Sr}$ and $\mathrm{Ca}$ concentration one can easily tune the $\mathrm{T}_{\mathrm{MI}}$ to room temperature. As shown is Fig. 2, the $\mathrm{T}_{\mathrm{MI}}$ increases with $\mathrm{Sr}$ concentration in $\mathrm{La}_{0.7} \mathrm{Ca}_{0.3-\mathrm{x}} \mathrm{Sr}_{\mathrm{x}} \mathrm{MnO}_{3}$. But the sharpness of transition decreases that could be recovered by reducing the intergrain tunnel resistance. As in $\mathrm{FM} /$ metallic region the intergrain barrier in granular perovskite behaves as nonmagnetic as well as nonconducting. So the double-exchange interaction, which is often used to explain the conductive behavior of manganite, becomes weaker on the surfaces of grains. However with the help of external field or by producing a conducting channel between the grains the tunnel resistance can be reduced. It is believed that if it may possible than granular perovskite can have large value of TCR and can behave like tunnel-GMR. In order to enhance the sharpness/intergrain conductivity, silver has been added to the pristine samples. Metallic silver having low melting point will help during sintering process (liquid phase sintering) and also segregates at the grain boundaries creating conducting channels. The SEM micrograph of pure and Ag-doped sample of LCS10MO are shown on Figs. 3(a) and 3(b). These figures clearly indicate that sample with silver as additives have better grain growth and connectivity. The $\mathrm{T}_{\mathrm{MI}}$ remains nearly constant with silver addition ${ }^{5,8}$ though sharpness improves. Inset is showing the TCR (measure of sharpness) as a function of temperature for $\operatorname{LCMOAg}(0.4)$ and LCS10MOAg (0.2) composition. The maximum TCR $(\sim 15 \% / \mathrm{K})$ is obtained for $\operatorname{LCMOAg}(0.4)$ but below room temperature. For uncooled operations, room temperature high TCR is required. A $\sim 9 \% / \mathrm{K}$ value of TCR above room temperature is obtained for $\operatorname{LCS} 10 \operatorname{MOAg}(02)$, which is the optimum value of TCR achieved in the case of $\mathrm{La}_{0.7} \mathrm{Ca}_{0.2} \mathrm{Sr}_{0.1} \mathrm{MnO}_{3}: \mathrm{Ag}_{\mathrm{y}}$ compounds. In polycrystalline bulk samples, a $\sim 9 \% / \mathrm{K}$ value above room temperature is quite reasonable. Moreover, further optimization of samples as a thin film can yield good and encouraging results for application purposes.

As far as magnetic measurements are concerned, in $\mathrm{La}_{2 / 3} \mathrm{Ca}_{1 / 3} \mathrm{MnO}_{3}: \mathrm{Ag}$ system, the para-FM transition temperature $\left(\mathrm{T}_{\mathrm{C}}\right)$ remains almost constant for all compositions. ${ }^{5}$ But 


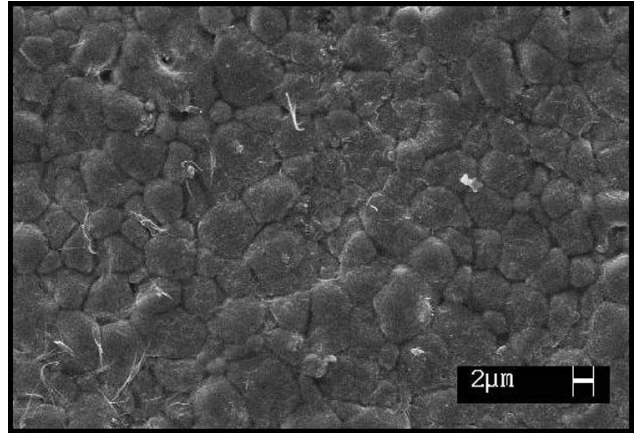

(a)

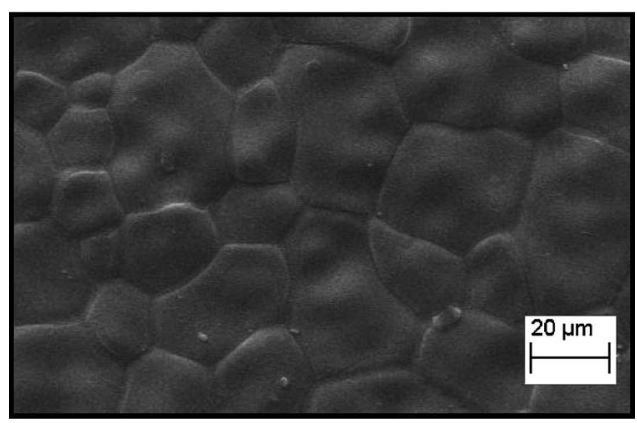

(b)

FIG. 3. SEM micrograph of (a) $\mathrm{La}_{0.7} \mathrm{Ca}_{0.2} \mathrm{Sr}_{0.1} \mathrm{MnO}_{3}$ and (b) $\mathrm{La}_{0.7} \mathrm{Ca}_{0.2} \mathrm{Sr}_{0.1} \mathrm{MnO}_{3}: \mathrm{Ag}_{0.2}$.

$\mathrm{T}_{\mathrm{C}}$ varies slightly for $\mathrm{L}_{0.7} \mathrm{Ca}_{0.2} \mathrm{Sr}_{0.1} \mathrm{MnO}_{3}+\mathrm{Ag}_{\mathrm{y}} \quad(\mathrm{y}=0,0.2$, 0.3 , and 0.4 ) compounds. The variation in $\mathrm{T}_{\mathrm{C}}$ can be correlated with slight substitution of $\mathrm{Ag}$ into the main matrix ( $\mathrm{Sr}$ being larger) or to the concept of mixed phase in manganites. ${ }^{11}$ As shown in Fig. 4, there is large change in the resistivity values of $\operatorname{LCS} 10 \mathrm{MO}(\mathrm{Ag} 0.2)$ with applied field. The change in the resistivity with applied field has been calculated in terms of MR (inset Fig. 3). For application point of view, LFMR is required since high magnetic fields are not easily accessible. In our samples, high MR at low field has been observed for LCS10MO silver samples. For $\operatorname{LCS} 10 \mathrm{MOAg}(0.2)$ samples, the observed MR is about $\sim 30 \%$ at room temperature under applied field of $10 \mathrm{kOe}$ which is quite high at room temperature under low field. The maximum MR value for pristine $\mathrm{La}_{0.7} \mathrm{Ca}_{0.2} \mathrm{Sr}_{0.1} \mathrm{MnO}_{3}$ is nearly $16 \%(10 \mathrm{kOe})$ and that of $\operatorname{LCMOAg}(0.4)$ is $10 \%(10$ $\mathrm{kOe})$ at $300 \mathrm{~K}$. With such a high LFMR values for

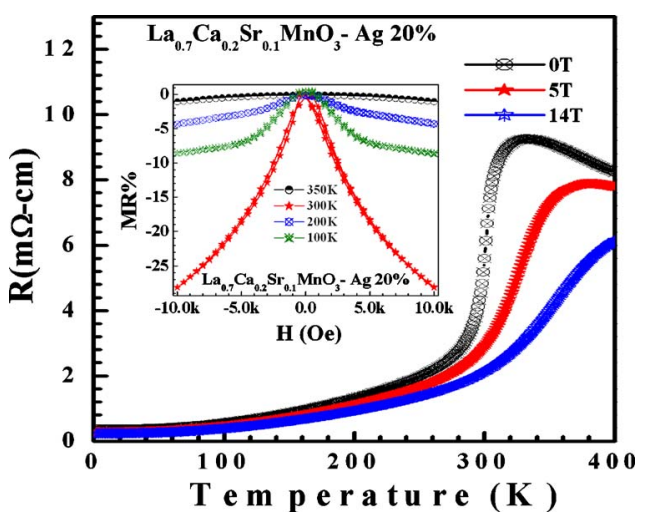

FIG. 4. (Color online) Resistivity plots of $\mathrm{La}_{0.7} \mathrm{Ca}_{0.2} \mathrm{Sr}_{0.1} \mathrm{MnO}_{3}: \mathrm{Ag}_{0.2}$ under applied field of 0,7 , and $14 \mathrm{~T}$. Inset shows $\mathrm{MR}$ percent of $\mathrm{La}_{0.7} \mathrm{Ca}_{0.2} \mathrm{Sr}_{0.1} \mathrm{MnO}_{3}: \mathrm{Ag}_{0.2}$ at fixed temperatures of 100, 200, 300, and 350 $\mathrm{K}$.

$\mathrm{La}_{0.7} \mathrm{Ca}_{0.2} \mathrm{Sr}_{0.1} \mathrm{MnO}_{3}: \mathrm{Ag}_{\mathrm{y}}$, with optimum value at $\operatorname{Ag}(0.2)$,can be explored and further optimized for industrial purposes.

In summary we have optimized both high TCR $(\sim 9 \% / \mathrm{K})$ and LFMR $(\sim 30 \%$ at $10 \mathrm{kOe})$ at room temperature for $\mathrm{La}_{0.7} \mathrm{Ca}_{0.2} \mathrm{Sr}_{0.1} \mathrm{MnO}_{3}+\mathrm{Ag}$ (0.2) compound. The studied materials could be the potential candidates for room temperature bolometer (high TCR) and magnetic sensor (high $\mathrm{MR})$.

${ }^{1}$ R. von Helmolt, J. Wocker, B. Holzapfel, M. Schultz, and K. Samver, Phys. Rev. Lett. 71, 2331 (1993).

${ }^{2}$ S. Jin, T. H. Tiefel, M. McCormack, R. A. Fastnacht, R. Ramesh, and L. H. Chen, Science 264, 413 (1994).

A.-M. Haghiri-Gosnet and J.-P. Renard, J. Phys. D 36, R127 (2003).

${ }^{4}$ R. Shreekala, M. Rajeshwari, S. P. Pai, S. E. Lofland, V. Smolyaninova, K. Ghosh, S. B. Ogale, S. M. Bhagat, M. J. Downes, R. L. Greene, R. Ramesh, and T. Venkatesan, Appl. Phys. Lett. 74, 2857 (1999).

${ }^{5}$ V. P. S. Awana, R. Tripathi, S. Balamurugan, H. Kishan, and E. TakayamaMuromachi, Solid State Commun. 140, 410 (2006).

${ }^{6}$ Y.-H. Huang, C. H. Yan, F. Luo, W. Song, Z.-M. Wang, and C.-S. Liao, Appl. Phys. Lett. 81, 76 (2002)

${ }^{7}$ M. Rajeswari, A. Goyal, A. K. Raychaudhuri, M. C. Robson, G. C. Xiong, C. Kwon, R. Ramesh, R. L. Greene, T. Venkatesan, and S. Lakeou, Appl. Phys. Lett. 69, 851 (1996).

${ }^{8}$ R. Tripathi, V. P. S. Awana, N. Panwar, G. L. Bhalla, H. U. Habermier, S. K. Agarwal, and H. Kishan, J. Phys. D 42, 175002 (2009).

${ }^{9}$ R. Tripathi, V. P. S. Awana, H. Kishan, and G. L. Bhalla, J. Magn. Magn. Mater. 320, L89 (2008).

${ }^{10}$ A. S. Sefat, M. A. McGuire, B. C. Sales, R. Jin, J. Y. Howe, and D. Mandrus, Phys. Rev. B 77, 174503 (2008).

${ }^{11}$ E. Dagotto, New J. Phys. 7, 67 (2005). 